Cahiers $d u$ MONDE RUSSE

\section{Cahiers du monde russe}

Russie - Empire russe - Union soviétique et États indépendants

$52 / 4 \mid 2011$

Varia

\title{
Scott M. Kenworthy, The Heart of Russia
}

\section{Pierre GONNEAU}

\section{OpenEdition \\ Journals}

Édition électronique

URL : http://journals.openedition.org/monderusse/7669

DOI : 10.4000/monderusse.7669

ISSN : $1777-5388$

Éditeur

Éditions de l'EHESS

\section{Édition imprimée}

Date de publication : 20 décembre 2011

Pagination : 828-830

ISBN : 978-2-7132-2353-2

ISSN : $1252-6576$

\section{Référence électronique}

Pierre GONNEAU, « Scott M. Kenworthy, The Heart of Russia », Cahiers du monde russe [En ligne], 52/4 | 2011, mis en ligne le 13 septembre 2013, Consulté le 25 septembre 2020. URL : http://

journals.openedition.org/monderusse/7669; DOI : https://doi.org/10.4000/monderusse.7669

Ce document a été généré automatiquement le 25 septembre 2020

〔c École des hautes études en sciences sociales 


\title{
Scott M. Kenworthy, The Heart of Russia
}

\author{
Pierre GONNEAU
}

\section{RÉFÉRENCE}

Scott M. KENWORTHY, The Heart of Russia. Trinity-Sergius, Monasticism, and Society after 1825. Washington, D.C. - New York : Woodrow Wilson Center Press, Oxford University Press, 2010, $\mathrm{xv}+528 \mathrm{p}$.

1 Les différents aspects du monachisme russe ont suscité une abondante bibliographie en langues occidentales et la Trinité Saint-Serge a été particulièrement bien servie en ce domaine. Parmi les plus récentes publications, il suffit de citer le livre de David B. Miller (Saint Sergius of Radonezh, his Trinity monastery and the formation of the Russian identity, DeKalb, IL : Northern Illinois University Press, 2010), paru la même année que l'objet de cette recension. Scott Kenworthy, spécialiste du comparatisme dans le domaine religieux, avait déjà publié une importante recension critique intitulée "Monasticism in Russian History" dans Kritika: Explorations in Russian and Eurasian History, 10 (2), Spring 2009, p. 307-331. Son propos actuel est original par le choix de la période considérée et la méthode suivie. En effet, l'auteur envisage l'histoire de la Trinité au cours des deux derniers siècles, de 1825 aux années 2000. La plupart des autres travaux se cantonnent dans des époques plus reculées et ne rassemblent pas dans la même perspective les époques tsariste, soviétique et même postsoviétique. En ce sens, S. Kenworthy suit la voie tracée par des études plus généralistes, comme F.X. Coquin (Des pères du peuple au père des peuples : la Russie de 1825 à 1929, P. : SEDES, 1991), J.-J. Marie (La Russie 1856-1956, P. :Hachette, 1997) ou G. Sokoloff (La Puissance pauvre : une histoire de la Russie de 1815 à nos jours, P. : Fayard, 1993). Du point de vue méthodologique, S. Kenworthy tente de concilier l'histoire spirituelle et la sociologie de la religion. L'ensemble s'ordonne en dix chapitres plutôt denses. L'auteur a consulté une abondante bibliographie de sources imprimées (mémoires d'ecclésiastiques, rapports administratifs, périodiques) et de travaux. Il a en outre utilisé plusieurs fonds 
d'archives de Moscou et Saint-Pétersbourg. La liste, donnée p. 483-484, comprend les fonds du saint-synode et de son ober-prokuror, du Concile de l'Église orthodoxe russe de 1917-1918 et des commissions et conseils qui ont administré les affaires religieuses en Union soviétique et en Russie, les dossiers personnels des supérieurs du monastère et de leurs principaux adjoints, comme Leonid (Kavelin), Filaret (Drozdov), Nikon (Roždestvenskij), ou encore de l'historien de l'Église russe et de la Trinité E.E. Golubinskij.

2 Le premier chapitre résume l'histoire du monachisme en Russie depuis la période moscovite, marquée par la fondation du monastère de la Trinité par Serge de Radonež († 1392). L'auteur pose dès le début les problématiques du renouveau et du déclin et des contradictions entre les écoles historiques à ce propos. Il conteste le cliché d'une Église orthodoxe russe «moribonde et corrompue» à la veille de 1917 (p. 5). Certes, elle traversait une période de remise en question, y compris interne, mais le mouvement monastique connaissait plutôt un nouvel essor et la société était loin de tendre tout entière vers la sécularisation. En outre, le nationalisme russe de l'époque n'était pas en conflit avec le sentiment religieux, bien au contraire. La Trinité Saint-Serge peut paraître un choix étrange pour illustrer le renouveau religieux du XIXe et début $\mathrm{Xx}^{\mathrm{e}}$, tant elle semble située sur le versant officiel de l'Église russe. Pourtant, l'étude de son cas montre que ses responsables surent faire preuve d'un remarquable esprit d'adaptation aux opportunités et aux besoins de leur temps (p.7). Les termes «profits» et «investissements» (p. 27) peuvent paraitre rudes aux oreilles des spécialistes de la spiritualité orthodoxe. Mais ils s'accordent avec " philanthropie » et « charité » (p. 56). Le chapitre 2 met en scène les deux responsables qui, par la conjugaison de leurs talents, rénovèrent la Trinité entre 1822 et 1877, le métropolite de Moscou Philarète (Drozdov) et l'archimandrite Antoine (Medvedev). Sous leur administration, la confrérie passa d'une centaine de moines à trois cent soixante-dix (p. 42). Philarète et Antoine faisaient preuve, en fait, des mêmes qualités que les abbés et cellériers des $\mathrm{XV}^{\mathrm{e}}$ et $\mathrm{XVI}^{\mathrm{e}}$ siècles et leur action suscita les mêmes critiques contre la richesse de l'Église qu'à l'époque de la polémique entre stjažateli et nestjažateli (p. 53-56). Il est intéressant de noter que l'intervention de la Trinité dans ce que l'on appellerait les œuvres sociales (hébergement et soin des malades et pèlerins, ouverture d'écoles, distribution de repas et d'aumônes) a été le résultat d'un véritable «éveil » à ces problématiques, dû à Antoine (p. 58). Philarète, qui exerçait aussi la responsabilité de métropolite de Moscou, était plutôt réticent au début, considérant que cette sphère relevait de la responsabilité de l'État. Ce dilemme s'est répété à la période soviétique (où l'État interdit à l'Église toute activité sociale), puis dans la Russie actuelle (depuis la perestroïka, à la demande de l'État, l'Église est de plus en plus présente en ce domaine). Les qualités de gestionnaire d'Antoine l'empêchèrent d'accéder à la retraite contemplative à laquelle il aspirait, mais que Philarète lui mesura chichement, à raison de vingt-quatre heures par mois (p. 44)... Antoine réussit pourtant à faire avancer la cause de la béatification de Séraphin de Sarov, et ce malgré les réticences évidentes du saint-synode vis-à-vis de ce saint proclamé par la vox populi (p. 43). Les chapitres 3 à 7 envisagent l'interaction complexe entre la communauté monastique et les croyants qui, en nombre de plus en plus considérable, effectuent le pèlerinage de la Trinité. Le monachisme à la Trinité au $\mathrm{XIX}^{\mathrm{e}}$ siècle est bel et bien un phénomène vivant et l'une des forces motrices d'une population paysanne qui accède davantage aux ordres religieux après en avoir été presque écartée par son statut de taillable. Il ne faut pas oublier les élites qui sont de nouveau touchées par la spiritualité orthodoxe. On lit avec intérêt les passages ayant 
trait aux réalisations architecturales qui illustrent les recherches spirituelles d'alors. Déjà, le métropolite Platon (Levšin) avait aménagé le monastère de Béthanie, son lieu de retraite particulier, au centre duquel se trouve une église de la Transfiguration dont le chœur, sans iconostase, se veut la réplique du Mont-Thabor (p. 29-30). Antoine fait ensuite construire l'ermitage de Gethsémani (ch.3). Dans les deux cas, on trouve un parallèle frappant avec le patriarche Nikon (1652-1658) qui avait fondé un monastère de la Nouvelle Jérusalem sur l'Istra, avec pour abbatiale une réplique du Saint-Sépulcre. On voit comment, après cette première expérience inaboutie, la Terre Sainte est transposée dans la Sainte Russie.

3 Les trois derniers chapitres décrivent le bref face-à-face des années 1917-1921, où les rapports entre l'État bolchevik et l'Église sont redéfinis de façon drastique, le «Golgotha » des années de terreur 1921-1938, puis l'improbable résurrection religieuse qui s'amorce à partir de 1943. Le dernier chapitre est sans doute trop court, mais l'auteur arrive au terme d'un long pèlerinage ! Il s'agit plutôt de quelques repères sur la mutation qui mène du « concordat stalinien » à un stade où, selon l'auteur, l'Église est le seul acteur social dans la Russie postsoviétique capable d'organiser une commémoration des victimes des persécutions soviétiques et en particulier de la terreur stalinienne (p. 382). On peut discuter certaines des thèses de S. Kenworthy (que nous reproduisons dans leur langue originale pour ne pas les trahir) "Since the collapse of the Soviet Union in 1991, the Orthodox Church has attempted to recover the past that the Bolsheviks tried to destroy, together with attempting to recapture Russia's present and shape its future » (p. 383), «the repeated pattern of monasticism's revival that follows each attempt to suppress it, from the eighteenth to the twentieth centuries, suggest that monasticism was not merely a phenomenon peculiar to the Middle Ages but rather is something central, even intrinsic, to Russian Orthodoxy» (p. 385). On peut qualifier le monachisme de phénomène "populaire», si l'on considère le nombre de vocations qu'il suscitait à la veille de la révolution russe et qu'il suscite de nos jours, mais il ne faut pas non plus oublier que le monachisme est le vivier dans lequel se forment les prélats de l'Église russe, il est donc autant une étape dans la carrière ecclésiastique qu'une vocation définitive. L'idée que le monachisme « peut de nouveau contribuer à la régénération du peuple russe » (p. 387) est séduisante dans la mesure où elle dessine une sorte de retour aux sources et de réconciliation avec l'histoire. Il reste à savoir si la Russie a résolu de façon durable le problème de la relation entre l'État et l'Église, la sphère profane et la sphère religieuse. 